\title{
THE SPREAD OF NEWTONIAN AND LEIBNIZIAN NOTATIONS OF THE CALCULUS.
}

BY PROFESSOR FLORIAN CAJORI.

(Read before the American Mathematical Society April 9, 1921.)

THE bitter controversy over the invention of the calculus is generally supposed to have eliminated the Leibnizian notation from Great Britain down to the time of Woodhouse, Peacock, Herschel and Babbage, and to have prevented the use of the Newtonian notation on the European continent. It is the purpose of this article to point out the extent to which this general impression is in need of revision and also to indicate the spread of these notations in America.

1. Leibnizian Notation in Great Britain. Several years before Newton permitted his theory of fluxions and his notation for fluxions and fluents to see the light of day in printed form, his friend, John Craig, used the notation of Leibniz, $\mathrm{dp}, \mathrm{dx}, \mathrm{dy}$, in a book, the Methodus Figurarum published in 1685 in London. Craig employed the Leibnizian notation again in 1693 in another booklet, the Tractatus Mathematicus, as well as in articles printed in the Philosophical TransacTIONL OF LONDON for the years 1701, 1703, 1704, 1708; his article of 1703 contains the sign of integration $\mathcal{S}$. In the Transactions for 1704-05, an article by John Bernoulli makes extensive use of the Leibnizian signs. In 1716 the English physician and philosophical writer, George Cheyne, brought out in London the Philosophical Principles of Religion, Part II, which contains a chapter from the pen of John Craig on a discussion of zero and infinity, dated September 23, 1713. In this chapter Craig uses Leibniz's symbols for differentiation and integration. But in 1718 Craig made a complete change. In that year he issued a book, De Calculo Fluentium, in which he switches over to the exclusive use of the Newtonian notation. Evidently this change is a result of the controversy then raging between the supporters of Newton and Leibniz.

In volume 23 of the Philosophical Transactions of LonDon, for the years 1702 and 1703, De Moivre uses dots for fluxions, but in integration he uses the Leibnizian sign $\int$. Thus, on page 1125, De Moivre writes "adeoq; $\dot{q}=\frac{3}{2} d v^{2} \dot{v}-\frac{3}{2} d v^{2} \dot{y}$, igitur $q=\frac{1}{2} d v^{3}-\int_{2}^{3} d v^{2} \dot{y}$. Ergo ad hoc perventum est ut 
fluentum quantitatem inveniamus cujus fluxio est $\frac{3}{2} d v^{2} \dot{y}$." Evidently his partisanship favoring Newton did not at this time prevent his resorting to the convenience of using the Leibnizian symbol of integration.

Even John Keill, who fought so prominently and unskillfully on the side of Newton, employed a similar mixed notation. In a paper, dated November 24, 1713, and printed in the Philosophical Transactions for 1714-16, he adopts the symbolism " $\int \phi \dot{x}$ ". A mixture of Continental and British symbols is found in the writings of E. Waring and much later in Olinthus Gregory's Treatise of Mechanics (3rd Ed., London, 1815) where on page 158 there is given " $\int d y \sqrt{ }\left(\dot{x}^{2}+\dot{y}^{2}\right) . "$ In times still more recent the Newtonian dot has been used to advantage, by the side of Leibnizian symbols, in the treatment of mechanics and the algebras of vectors.*

Returning to the eighteenth century, we find Benjamin Robins $\dagger$ writing the Leibnizian signs in a review of a publication of Leonhard Euler. Joseph Fenn, an Irish writer, little known, who had studied on the Continent, and was at one time professor of philosophy in the University of Nantes, issued at Dublin soon after 1768, a History of Mathematics. In it Fenn has occasion to use the calculus, and employs the Leibnizian notation. In a Plan of the Instructions given in the Drawing School established by the Dublin Society (p. LXXXIX of the above volume) he discusses the tides, and, in finding the greatest height of the tides, he uses the calculus and the notation of Leibniz. He uses them again in his Second Volume of the Instructions given in the Drawing School established by the Dublin Society, Dublin, 1772. He is friendly to Newton, uses the terms "fluxion" and "fluent," but never uses Newton's notation. He is perhaps the last eighteenth century writer in Great Britain who used the symbolism of Leibniz.

From our data it is evident that the Leibnizian notation was the earliest calculus notation in England which appeared in print, that in rare instances it was used by certain Englishmen, but that it vanished almost completely from British soil in the latter part of the eighteenth ceritury.

\footnotetext{
* See, for example, P. G. Tait's Elementary Treatise on Quaternions, 2nd Ed., 1873, Chapter X; T. Hayashi in this Bulletin, vol. 26, 1919, p. 74 . † Benjamin Robins, Remarks on Mr. Euler's Treatise on Motion, Dr. Smith's Compleat System of Opticks, and Dr. Jurin's Essay upon Distinct and Indistinct Vision, London, 1739.
} 
2. Newtonian Notation in Continental Europe. That Newton's notation would be reproduced in editions of his works printed on the European continent is to be expected. Thus the fluxional symbols appear in J. Castillon's edition of Newton's mathematical works, brought out at Lausanne and Geneva in 1744, and in the appendix to the second volume of Castillon's edition of Newton's Arithmetica Universalis, Amsterdam, 1761. John Muller, a German by birth, who was appointed master of the Royal Military Academy at Woolwich and became "the scholastic father of all the great engineers this country (England) employed for forty years," brought out in 1736 in London a book entitled A Mathematical Treatise: Containing a System of Conic-Sections; with the Doctrine of Fluxions and Fluents. Muller translated his own book into French and had it published at Paris in 1760 . The French as well as the English editions used the Newtonian symbols. An article from the pen of David Gregory at Oxford, after its appearance in the Philosophical Transactions of London, was republished in 1697 in the Acta Eruditorum of Leipzig, the British fluxional symbols being faithfully reproduced. This procedure is no more unusual than was the printing of John Bernoulli's article in the PhILOsophical Transactions of 1704-05. The fluxional notation is given in full in the article "Fluxions" in Alexandre Savérien's Dictionnaire Universel de Mathématique et de Physique, Paris, 1753. We proceed to more startling disclosures.

After the middle of the eighteenth century when feelings of resentment ran high between the adherents of Leibniz and their opponents, it is extraordinary that a mathematical journal should have been published on the European continent for fifteen years which often uses the Newtonian notation, but never uses the Leibnizian. It is more surprising still, that no reference is made to this fact in any history of mathematics, though many volumes have been written which deal with various phases in the evolution of the calculus. The journal in question is a monthly, published at Amsterdam from 1754 to 1769 . It appeared under the title, Maandelykse Mathematische Liefhebbery (Monthly Mathematical Recreations). Each issue contained about forty pages. It is mentioned in Cantor's history,* but otherwise has not attracted

* M. Cantor, Vorlesungen über Geschichte der Mathematik, Vol. IV, Leipzig, 1908, p. 70. 
the attention of writers on the general history of mathematics. This neglect is due, probably, to its appearing in the Dutch language and devoting itself to the solution of elementary problems on algebra, arithmetic and geometry, and to the publication of school items of only local interest. It contains problems on maxima and minima, solved with the aid of fluxions dressed in the familiar garb of the Newtonian dots. The first twelve volumes of the journal give altogether fortyeight or more such problems; the last few volumes contain no fluxions. About seventeen different writers contributed fluxional solutions. Some writers give only their initials; none of them are men of note. It was a time when the Netherlands did not have great mathematicians. Huygens had died in 1695; Hudde in 1704; Nieuwentijt in 1718. Among the contributors using fluxions were G. Centen, J. Schoen, J. Kok, J. T. Kooyman, F. Kooyman, A. Vryer, J. Bouman, D. Bocx. The two most noted where P. Halcke, and Jakob Oostwoud. The latter was editor of the monthly during the first twelve years. Oostwoud was a teacher of mathematics in Oost-Zaandam near Amsterdam, who in 1766 became member of the Hamburg Mathematical Society.* Later he collected and published the problems solved in his journal in three separate volumes. $\dagger$

3. Calculus Notations in the United States. In the United States the early influence was predominantly English. Wherever higher analysis received attention, it was in the form of the fluxions of Newton. Before 1766 occasional studies of conic sections and fluxions were undertaken at Yaleł under the inspiring leadership of President Clap. Perhaps as early as 1795, and again in 1802, Jared Mansfield published at New Haven, Conn., a volume of Essays, Mathematical and Physical, which includes a part on "fluxionary analysis." In a footnote, on page 207 , he states that the fluxions of $x, y, z$ are

* Bierens de Haan in Festschrift, herausgegeben von der Mathematischen Gesellschaft in Hamburg, anlässlich ihres 200 jährigen Jubelfestes 1890. Erster Teil, Leipzig, 1890, p. 79.

$\dagger$ Bierens de Haan, op. cit., p. 80, where the titles of the three publications are given in full. See also de Haan's Bouwstoffen voor de Geschiedenis der Wis-en Natuurkundige Wetenschappen in de Nederlanden, 1878, p. 7685, reprinted from Verslagen en Mededeelingen der Kon. Akademie van Wetenschappen, Afd. Natuurk., $2^{\circ}$ Reeks, Deel VIII, IX, X en XII.

$\ddagger$ Yale College; a Sketch of its History, by William L. Kingsley, Vol. II, pp. $497-498$. 
usually denoted "with a point over them, but we have here denoted these by a point somewhat removed to the right hand," thus $x$. A similar variation occurs in Robert Woodhouse's Principles of Analytical Calculations, Cambridge (England), 1803, p. XXVII, where we read, "Again $\frac{\ldots}{x y}$ or $(x y)$ '. is not so convenient as $d^{3}(x y)$."

In 1801 Samuel Webber, then professor of mathematics and later president of Harvard College, published his Mathematics compiled from the Best Authors. In the second volume he touched upon fluxions and used the Newtonian dots. This notation occurred also in the Transactions of THE AMERICAN Philosophical Society, of Philadelphia, in an article by Joseph Clay who wrote in 1802 on the "Figure of the Earth." It is found also in the second volume of Charles Hutton's Course of Mathematics, American editions of which appeared in 1812, 1816(?), 1818, 1822, 1828 and 1831.

An American edition of S. Vince's Principles of Fluxions appeared in Philadelphia in 1812. That early attention was given to the study of fluxions at Harvard College is shown by the fact that in the interval 1796-1817 there were deposited in the college library twenty-one mathematical theses which indicate by their titles the use of fluxions.* These were written by members of Junior and Senior classes. The last thesis referring in the title to fluxions is for the year 1832 .

At West Point, during the first few years of its existence, neither fluxions nor calculus received much attention. As late as 1816 it is stated in the West Point curriculum that fluxions were "to be taught at the option of professor and student." In 1817, Claude Crozet, trained at the Polytechnic School in Paris, became teacher of engineering. A few times, at least, he used in print the Newtonian notation, as, for instance, in the solution, written in French, of a problem which he published in the Portico, of Baltimore, in 1817. Robert Adrain, later professor in Columbia College and also at the University of Pennsylvania, used the English notation in his earlier writings, for example, in the third volume of the Portico, but in Nash's Ladies and Gentlemen's Dairy, No. II, published in New York in 1820, he employs the $d x$.

A slight deviation from the Newtonian forms is found in

* Justin Winsor, Bibliographical Contributions, No. 32. Issued by the Library of Harvard University, Cambridge, 1888. 
articles on the theory of fluxions, contributed by Elizur Wright of Tallmadge, Ohio, to the American Journal of ScIENCE AND ARTs, for the years 1828, 1833, 1834. Like Mansfield, he does not place the dot exactly over the variable, but a little to the right, where ordinarily exponents are put. Thus, the fluxion of $x$ is $x$; the first, second and third fluxions of $x^{3}$ are, respectively, $3 x^{2} x^{\circ} ; 6 x x^{2}, 6 x^{3}$. After 1830 the Newtonian fluxional system is rarely encountered in the United States.

In the American Journal of Science and Arts, the earliest paper giving the Leibnizian symbols was prepared by Professor A. M. Fisher of Yale College. It is printed in Volume 5 (1822) and is dated August, 1818.

The earliest articles in the Memorrs of the American ACADEMY OF ARTS AND SCIENCES which contain the "d-istic" signs bear the date of 1818 and were from the pens of F. T. Schubert and Nathaniel Bowditch.* The latter came to know the calculus on long sea voyages during the years 1795 to 1804, when he studied Lacroix's Calculus. Bowditch began his translation of Laplace's Méchanique Céleste in 1814. In the Memorrs mentioned above, Theodore Strong of Rutgers College began in 1829 to publish a series of papers containing solutions of problems, involving the Leibnizian symbolism.

The articles contributed by Fisher, Schubert, Bowditch and Strong were isolated papers which were not accessible to the mass of students in mathematics. The publication which placed the Leibnizian calculus and notation within reach of all and which marks the time of the real beginning of their general use in the United States, was the translation from the French of Bezout's First Principles of the Differential and Integral Calculus, made by John Farrar of Harvard University in 1824. Between 1824 and 1831 five mathematical theses were prepared at Harvard which contain in their titles the words "Differential Calculus" or "Integral Calculus." $\dagger$ After 1824 French influences dominated all instruction in higher analysis at Harvard.

From what we have stated it appears that the movement toward the introduction of continental analysis began in America about ten years later than it did in England.

University of CaLifornia.

* Memoirs of the American Academy of Arts and Sciences, Vol. 4, Part I, Cambridge, Mass., 1818, pp. 5, 47.

$\dagger$ Justin Winsor, op. cit. 